This is a pre-print version of the article. To obtain the published version, please use this reference:

Fjær, E. G., \& Tutenges, S. (2017). Departies: conceptualizing extended youth parties. Journal of Youth Studies, 20(2), 200-215.

\title{
Departies: Conceptualizing extended youth parties
}

\begin{abstract}
Every year, millions of young people travel away from home to party for days or weeks on end in permissive environments, such as music festivals, dance parties, and nightlife resorts. The studies that have been conducted on these extended youth parties have focused primarily on specific risk-taking behaviors, such as drug use and violence. Here, we scrutinize the research on extended youth parties to identify general changes that young people undergo at these events. We call these celebrations departies, because they center on the organization and facilitation of momentary departures from the participants' everyday life. Participants depart (1) spatially, by traveling to locations that are constructed as sites of opportunity and excess; (2) temporally, by partying for several days in a row and focusing on immediate gratifications; (3) morally, by engaging in activities that are widely deemed immoral; (4) stylistically, by altering their stylistic expressions through dress, demeanor, and consumption; and (5) experientially, because the parties generate mood and mind alterations. These are overlapping and intertwined elements, the combination of which amounts to a distinct type of youth party. Departies constitute exceptional events in the lives of many young people, and ought to be studied from a comparative perspective.
\end{abstract}


Keywords: Alcohol, Drugs, Tourism, Nightlife, Risk, Youth

\section{Introduction}

Every year, millions of young people across the Western world leave their homes to party with peers in permissive environments, such as 'Spring Break' destinations in North and South America (Monterrubio, Josiam, and Duncan 2015); 'Schoolies week' destinations in Australia (Maticka-Tyndale, Herold, and Oppermann 2003); nightlife resorts in Southern Europe (Hughes et al. 2009); ski resorts (Thorpe 2011); music festivals (Dilkes-Frayne in press); dance parties (St John 2009); and party buses, vans, trains, and ships (Dickerson 1996; Reference removed forthcoming).

These leisure activities have several features in common. Most importantly, they all involve a combination of traveling and celebration, and they all last for several days or weeks on end. They draw large crowds and involve high levels of alcohol and/or illegal drug use. Many young people spend a considerable amount of their leisure time and money on such events (Briggs 2013). They are vital for the construction of self-identity among segments of the youth population (Bhardwa 2014), and they occupy a central place in contemporary youth culture, including in literature, music, and television (e.g., Max 2012; Korine 2012; Tiësto 2007). These leisure activities are regularly reported in the media, where they are mainly portrayed from a critical and moralizing angle (Hier 2002, 51; St John 2009; Andriotis 2010). Finally, numerous studies have associated these activities with short- and long-term health problems (Hughes et al. 2009; Calafat et al. 2011).

In spite of these shared characteristics, research into these activities rarely takes a comparative perspective (however, see Hughes et al. 2008), and little effort has been made to develop concepts and theories capable of explaining and theorizing them (however, see Redmon 2003). The vast majority of research in this area is instead focused narrowly on small 
clusters of risk behavior, such as violent behaviors (Hughes et al. 2008), patterns of illicit drug use (Bellis et al. 2003), binge drinking (Reference removed 2008), HIV-risk behaviors (Apostolopoulos, Sönmez, and Yu 2002), and the purchase of sexual services (Reference removed 2011). These studies proceed by breaking up the leisure activities into separate parts, which are then subjected to close scrutiny.

Drawing on the existing research literature, including studies conducted by ourselves, we shift focus from the particularities to the commonalities of extended youth parties. We argue that these parties center on the organization, facilitation, and realization of momentary departures from the ordinary, and thus call them 'departies', a contraction of 'departure' and 'party'. Departies are a type of collective celebration that takes place for several days in a row in a permissive environment away from home. The departures of departies take multiple forms, of which this paper highlights the following: spatial, temporal, moral, stylistic, and experiential. These five types of departure are closely connected and overlapping, but we describe them one by one for the sake of clarity, and in order to construct a general concept that we hope will stimulate future research into extended celebrations among young people. The concept of departies is an ideal type, in the sense that it is a analytic invention of ours that does not correspond exactly to any single empirical case, but rather sums up and clarifies otherwise diffuse tendencies that can be observed in the empirical world (Weber 2011, 90; Frank 2013, 29). The concept is intended as a heuristic tool for youth, alcohol, and tourist researchers who wish to understand the subjective and intersubjective dynamics of what we consider to be a widespread, cross-cultural type of celebration.

\section{Spatial departures}

A key feature of departies is that they involve a geographical movement away from home. The spatial departures usually involve traveling to another country or state, something that 
was facilitated greatly during the 1960s, with the advent of cheap air travel (Mann 2013,6). Participants leave behind the constraints of school, work, and family life, and momentarily settle in environments designed for consumer excess and excitement. The travel itself is often an integral part of the event. Certain departies are, indeed, moveable feasts during which participants celebrate on the road in vehicles or by sea in 'booze cruise ships' (Reference removed forthcoming).

As a rule, departy spaces differ from the participants' normal habitats and local nightlife scenes because they attract, and are densely packed with, young people aiming at what has been emically referred to as 'having a blast' (Redmon 2003, 45), 'get smashed', or 'run amok' (Reference removed 2012). Departy spaces have the characteristics of 'backspaces' (Redmon 2003), meaning that these locations offer a sense of sanctuary from coercive authorities, such as parents, teachers, and senior colleagues. These environments 'provide an atmosphere of special piquancy' (Goffman 1986, 81), and temporarily enable visitors to participate in transgressions that they find difficult to perform outside of this context (Redmon 2003, 27). Although participants usually travel with friends, the mere fact being away from home can lead to 'situational disinhibition' (Apostolopoulos, Sönmez, and Yu 2002), because travelers tend to feel more anonymous (Shields 1990, 49; Brown and Stephan 2013) and because they are 'free of the built-in cues and spatialization' of their normal lives (Shields 1990, 49; Brown and Stephan 2013). It has been suggested that women are particularly appreciative of the anonymity of being away from home because they find themselves released and relieved from the traditional understanding of women as the decent gender and from their usual concern for their sexual reputation (Brown and Stephan 2013, 37; Reference removed 2012; Thomas 2005). Departy locations are construed as airtight gossip containers with slogans such as 'what happens in Ibiza stays in Ibiza', based on the premise that all departy antics will be kept secret to those who were not present (Thomas 2005; Briggs 
and Turner 2012; Thurnell-Read 2012; Reference removed 2012). This premise has become increasingly illusory, with departy antics now widely reported and fueled on social network sites and in the media (Eberhardt 2007; Niland et al. 2014; Ellen 2014).

The materiality, imagery and design of departy spaces significantly shape the activities that take place within them (Andrews 2009; Bøhling 2015; Jayne et al. 2012). Participants are, for example, provided with behavioral and experiential cues through advertisements that promote alcohol as the main road to heterosexual sex and fun while stigmatizing men as primitive hunters and women as their willing prey (Tan 2013). Many departies involve a dynamic movement between indoor spaces where participants are crammed together and outdoor spaces where they may move more freely (Sönmez et al. 2013). For example, pub crawl crowds walk from bar to bar (Thurnell-Read 2011; Reference removed 2015c), festivalgoers move between campsites and concert stages (Dilkes-Frayne in press), and road trip parties are marked by an alternation between time spent inside vehicles and time spent with larger crowds in parking lots (Reference removed forthcoming). This mobility ensures that departy participants are continuously exposed to new stimuli, different people and a variety of commercial products (e.g. alcohol beverages), all of which can prevent the extended celebrations from becoming monotonous while helping to create a sense of being on an adventure full of unforeseen and memorable happenings.

Departy spaces are typically, but not necessarily, commercialized. Many of them feature 'drinkatainment' activities (Bell 2008, 292), which revolve around the sale and consumption of alcoholic beverages. At nightlife resorts, for instance, tourists are offered 'party packages' that give access to an array of drinking events, such as pub crawls, foam parties, and karaoke nights (Sönmez et al. 2013). However, participants are never merely passive consumers of these parties, but always and necessarily contribute to them through their own performances (Duff 2008). At some departies, participants play an active role in 
transforming mundane, low-intensity spaces into party zones, as when high school students buy buses and turn them into mobile party scenes (Reference removed forthcoming), or when ravers appropriate and redefine an abandoned warehouse into an electronic dance party (Bey 1991; St John 2009).

This place-making also has a symbolic dimension. Departy spaces are constituted as 'play spaces' (Measham 2004) through the creation of 'place myths' (Shields 1990). Each departy bears a name, relating either to the type of celebration (e.g., Mardi Gras and Spring Break) or to the locality (e.g., Sunny Beach and Ayia Napa). Associated with these names are place myths that make people familiar with a departy even before having participated in it (Briggs et al. 2011, 34). Survey studies suggest that a key motivation for attending departies is to engage in nightlife activities such as dancing and drinking (Bellis et al. 2000, 237; Calafat et al. 2011, 11). Participants tend to prepare for this long before they leave home, for instance by talking about how 'fun' and 'wild' it is all going to be (Josiam et al. 1998). Part of these preparations involves constructing departy spaces as realms of opportunity, excess, and spectacular experiences (Briggs and Turner 2012; Apostolopoulos, Sönmez, and Yu 2002). This anticipation helps the participants tune into the turbulent energies that await them, making it easier to 'let loose' once the party itself kicks off (Duff 2010; Patrick et al. 2011; Apostolopoulos, Sönmez, and Yu 2002; Sönmez et al. 2006; Reference removed 2015c). The often long and costly journey to these events serves to heighten the anticipation, while demonstrating dedication and willingness on the part of the participants to make a sacrifice for the festivities (Jaimangal-Jones, Pritchard, and Morgan 2010, 257). The media and various commercial actors also contribute to the place-making, as they have an interest in constructing departy zones as infinitely fun and scandalous: sin sells (Andriotis 2010). These place myths can affect participants' perception of departy spaces to such an extent that the myths may 
remain unaltered even after having been contradicted by individuals' personal experiences (Ribeiro et al. 2009).

\section{Temporal departures}

Departies are a form of 'prolonged hedonism' (Goulding, Shankar, and Elliott 2002, 278) that lasts for several days or weeks in a row, with no or few breaks to rest and sober up. Whereas the day-to-day lives of contemporary youth tend to be highly structured, for example around set times for when to get up and when to be at school, departies often have few or highly flexible time schedules. There may be certain events that require presence within specific time periods (e.g., happy hour and hotel breakfasts), but participants often resist or fail to meet the demands of such schedules.

Unlike many other forms of celebration, such as concerts and New Year's Eve celebrations, departies last much longer than a single night, and this is part of their attraction (McRobbie 1994, 171). Every day and hour of the week is transformed into a potential time of 'fun' (Khan et al. 2000, 223). Many participants start drinking during the day, in part to relieve a hangover from the night before. Once the departy gets started they also get little sleep, and what little sleep that they do get tends to be at odd hours and places. These parties last so long and are prioritized so highly that many participants become sleep deprived, suffer increasingly from hangover symptoms, and require days or even weeks to recover once the party is over (Sönmez et al. 2013, 53; Reference removed 2015b). Novices often encounter problems with 'peaking too early' or 'burning out' before the festivities have ended, whereas more seasoned participants have in many cases developed strategies to better protect themselves and get rest, for instance by using earplugs, taking naps, or going regularly to 'chill out' areas (Dilkes-Frayne in press). 
Departies can have attributes of rites of passage, marking key milestones in life or celebrating youth itself as a period in life where one is expected to have fun, experiment, and accumulate experiences (van Gennep 1960; Sande 2002). Departies are widely perceived as life experiences on which one should not miss out, and which provide those who engage in them with lasting memories. As liminal phenomena, they are played out within a clearly defined time span; their duration may be defined, for example, by their organizers (e.g., a travel agency), or it may coincide with some public holiday. Typically, participants allocate their available time off from work or school to make time for their participation (Briggs and Turner 2012), but also '[t]he spatial movement concretiz[es] and ma[kes] convincing the temporal shift from the routinized schedules of workdays to non-routinized holidays' (Shields 1990, 48).

Because departies are limited to defined points in time and life where specific groups of people may participate — an occasion and window of opportunity — these party practices often mobilize participants who are determined not to miss out on potentially important experiences while they still have the opportunity to have them (Briggs and Turner 2012). Accordingly, participants may be dually motivated to participate, both by an anticipation of valuable experiences and a fear of future regret for not having seized the opportunity to acquire them (Apostolopoulos, Sönmez, and Yu 2002; Patrick et al. 2011). Commercial actors can capitalize on this by presenting a departy, and, by association, their product, as something that cannot be missed, or by presenting their product as a necessary element without which the departy will not be complete.

Departies are widely perceived as costly, unique, and bounded events that constitute an integral part of being young. This spurs the participants on to make the most of the limited time they have and to avoid wasting time on rest, practicalities, and deliberation (Thomas 2005). Participants tend to favor spontaneity over routine, flexibility over rigidity, and 
immediate gratification over long-term benefits. Focus is very much on the present, and on making the most of pleasures that are readily available and easily consumed. This 'ethics of the instant' (Maffesoli 2003), 'presentism' (Maffesoli 1989), or 'NOW!-ism’ (Reynolds 1998) is expressed through emic slogans such as 'YOLO' (acronym for 'You Only Live Once'), 'live like there's no tomorrow', and 'live hard, die young'. This now-emphasis goes hand in hand with a sort of 'YOLO' rationale or 'why-not' attitude, which makes participants more prone to take part in potentially dangerous, traumatizing, and morally degrading activities.

However, participants' preoccupation with representations of departy antics reveals that this lack of concern for past events or future consequences is not complete. In preparation for their own participation, they might relay to each other tales of departy activities they have heard about, or anticipate and plan for certain transgressions. Aware of the potential for generating entertaining stories, pictures, and videos, participants' antics often have clear selfreflective and performative elements, as when festival-goers drink from beer bongs in front of cameras or opponents say something funny in the middle of a fight (Briggs and Turner 2012; Reference removed 2013a). Social networking sites play an important role in keeping memories alive, as participants often spend lots of time online to revive and evaluate the event after it has ended (Robards and Bennett 2011; Truong 2015). These online activities may lead to the recruitment of new participants for future events, and provide indications as to how one is supposed to (mis)behave once the next departy kicks off. Reinforcing place myths, these representations disseminate definitions of departies as events where alternative behaviors are expected and permitted.

\section{Moral departures}

Participants in departies engage in alterations of the moral orders of everyday life (Briggs 2012; Bellis et al. 2000; Reference removed 2012, 2015b). People continually feel compelled 
to explore, challenge, and go beyond conventional moral commands (Bataille 2001, 63), and sometimes this is actively expected of them, most notably during times of intense celebration when deviant behavior is 'temporarily legitimated' (Redmon 2002, 381). Departy participants often reference the departy context as legitimizing or explaining participation in transgressive antics, which may diffuse responsibility and partially dissociate them from their actions (Briggs 2012; Reference removed 2015b, 2015a).

Departy spaces may be conceived as social laboratories, in which participants are enabled to experiment with prevailing norms and rules and where 'performative acts of imagination can be executed and new identities formed that then infuse and shape daily life' (O'Grady 2012, 101). What takes place at departies may be exported into the context of everyday life at home, for instance in the form of new leisure interests and consumptive practices. This observation has lead researchers to suggest, that data on risk-behaviors at leading nightlife resorts, such as Ibiza, may help understand and predict emerging trends in risk-behaviors elsewhere (Bellis et al. 2003).

However, departies do share many of the routine transgressions that take place on a weekly basis in local nightlife environments. Typically these involve the intake of large amounts of alcohol or other drugs (Bellis et al. 2003), public nudity (Forsyth 1992), simulated or actual sex (Redmon 2003), public urination, vomiting, and noise-making (Thurnell-Read 2011), risky games (Tremlett 2010), and vandalism (Calafat et al. 2011). Violence is common in certain departy settings (Hughes et al. 2008), but rarely is it endorsed or encouraged beyond a small section of participants.

A departy will often have one or more signature transgressions that have become its 'trademark' — such as the Mardi Gras tradition of exchanging beads for public nudity (Forsyth 1992). This means that participants arriving at a departy already have an idea of the transgressions that they are about to witness or commit (Milhausen, Reece, and Perera 2006, 
102; Sönmez et al. 2006, 904-5). They come prepared for the moral (dis)order of the departy, and this helps them negotiate the transgressions in which they are expected to engage (Reference removed 2015c). In preparation for the Norwegian high school graduation celebration, for instance, some students plan how they will lose their virginity through the signature transgression of having casual sex in a forest (Reference removed 2015a); similarly, individuals going to a music festival may decide that this will be the occasion for trying out an illicit drug (Reference removed 2010). Departies incite and enable participants to engage in deviant behaviors that would be difficult or impossible for them to undertake in the settings they normally inhabit.

However, participants do not simply enact the transgressions expected of them, but actively shape, reinvent, and uphold them through their own deviant performances. For example, some friendship groups invent competitions with rules whereby points are awarded, for example, for having sex with the most people or with the most unattractive individual, or for disrupting and causing embarrassment to a couple having sex (Reference removed 2015a, 2015b, 2012).

Departies are not simply occasions for the suspension of social norms, and nor do they imply a complete acceptance of extreme moral positions and reckless behaviors. On the one hand, because certain practice-specific transgressions are expected, those who do not partake in such transgressions are in effect behaving contrary to the alternative or modified moral order of the party practice (Reference removed 2015b). The most fundamental of these behaviors is drinking to intoxication and the corresponding censure of abstinence. On the other hand, alternative forms of behavior are not only enabled, but also restricted. There are norms regulating transgressions at departies too, and often it seems that moral boundaries have not been dissolved altogether, but simply moved. For example, paying for sex is approved by some but not others (Reference removed 2012), and even the signature 
transgressions of a departy may be construed as immoral and used as the basis of boundarywork (Reference removed 2015a).

The modified moral orders of departies thus make it possible to position oneself as a moderate participant, as the axes of 'moral space' (Hitlin 2007) are temporally expanded; the transgressiveness of departies expands the repertoire of symbolic boundaries that individuals can draw by offering even dedicated participants the opportunity to witness extreme transgressions enacted by others, or hear stories or myths about such transgressions, against which their own actions appear moderate (Bhardwa 2014; Reference removed 2013a, 2015a).

\section{Stylistic departures}

Departies involve departures from the participants' everyday style and aesthetics. This is expressed through alterations in dress, adornment, and demeanor that exhibit a symbolic investment in the departy (Jaimangal-Jones, Pritchard, and Morgan 2010). For example, nightlife tourists may adopt a beach persona, replete with sunglasses, minimal clothing, and hyper-sexualized comportment (Briggs 2012; Reference removed 2012); Mardi Gras participants may put on colorful masks and beads (Jankowiak and White 1999); groups of stag tourists often wear comical costumes (Thurnell-Read 2011); and Norwegian high-school students dress up in overalls and a distinctive cap (Reference removed 2015b). Through this direct engagement with the symbols of the departy, participants are visible to each other as participants and actively define the temporal period and spaces they inhabit as those of the departy practice. Similar stylistic departures extend to styles of music and dancing, and even to types of intoxicants, such as MDMA or cannabis, which allude to subcultures or neo-tribes 
that participants can temporarily visit (Bellis et al. 2000; Measham and Moore 2009; Reference removed 2010).

Often these engagements in stylistic departures center on performances underlining a collective identity, such as simple dance moves that anyone can do (Reference removed forthcoming, 2013b), songs or drinking games that everyone can be part of (Reference removed 2013b), scripted transgressions of established norms (Forsyth 1992), or the celebration of bodily reactions to the shared intoxication (Thurnell-Read 2011). Through these simple, playful, sometimes grotesque performances, participants may collectively depart from the relatively stable and responsible selves that they otherwise present. In this way, these playful performances amplify hedonistic excess and moral transgressions while allowing participants to experiment with normally hidden or suppressed dimensions of their social selves. Collectively, the 'wild' partying is displayed and the place myth confirmed, to other participants as well as nonparticipants (Thurnell-Read 2011; Reference removed 2015b, 2013b).

Departy spaces and participants are often characterized by seemingly indiscriminate dirtiness. Alcoholic beverages are poured over participants; dancing soaks everyone in sweat; foam, paint, or glitter is sprayed to cover everyone present; participants draw on each other's faces with markers; and fast food litters the streets, along with urinating or vomiting partygoers (Sönmez et al. 2013; Redmon 2003; Thurnell-Read 2011; Reference removed forthcoming, 2015c, 2013b). Through the dirtiness it causes, the stylistic departure of a departy also supports the sense of temporary moral immunity by erasing or blurring distinguishing marks, as participants are subject to the same 'processes of being ground down into a sort of homogenous social matter' (Turner 1977, 37). This collective, literal soiling mirrors the collective moral departure where everyone and no-one is held morally responsible because all are supposed to partake in the acts of cheerful indecency and degradation. 
Participants 'enter into a zone of indistinction' where they are 'transformed from citizen[s] into "almost animal" (Diken and Laustsen 2004, 102). This experience may be particularly liberating for young women, who are usually held to, and hold themselves to, demanding standards regarding make-up, dress, hair styling, and bodily appearance (Reference removed forthcoming).

Even so, gender differences tend to be emphasized more than downplayed at departies. Participants are almost constantly in close proximity to each other, on dance floors, in bars and clubs, on party cruises, at concerts, in pools, on beaches, in buses, and so on. The physical proximity, dancing to uninterrupted music, and warm weather heat up the participants' bodies, and this legitimizes minimal clothing while contributing to the sexualized atmosphere of departies (Diken and Laustsen 2004). Commercial actors may also contribute to this by requiring that their employees wear little clothing and flirt with customers (Reference removed 2012). Some women appreciate the permission to expose their bodies and publicly engage in activities which, outside the departy context, would be punished by 'slut-shaming' (Redmon 2003; Thomas 2005; Reference removed 2012, 2015a). However, departies are characterized by an intense objectification of female bodies (Andrews 2009), reflected in the widespread promotion of lap dances, strip shows and prostitution offered predominantly by female sex workers (Reference removed 2012). Gender identities are also emphasized and stereotyped through role-play, for instance, in 'Miss Wet T-shirt' contests and other scripted performances, which may include imitated or actual sexual behaviors (Ellen 2014; ThurnellRead 2011; Reference removed 2012).

\section{Experiential departures}

Departies are perceived as bounded occasions that offer the potential for exceptionally pleasurable and stimulating experiences (Miao, Lehto, and Wei 2013; Reference removed 
2012, 2015a). Departies center on 'high-intensity rituals' (Collins 2004, 149, 161) that may lead to significant alterations in how participants experience themselves, their surroundings, and other people. Accordingly, when describing departies, many participants use forceful expressions such as 'crazy' (Reference removed 2013b), 'mental', 'messy', 'fantastic', and 'not reality' (Briggs 2013), and it is widely agreed among participants that these parties provide 'room to be radically different' (St John 2001).

These experiences often have a strong 'orgiastic' element to them (Maffesoli 1985), in the sense that they are of an intensely passionate, sensuous, and erotic character (St John 2001), including when they emerge in same-sex heterosexual groups (Thurnell-Read 2011). These changes may not simply be of 'nuance and degree' (Durkheim 1995, 212-213), but can involve a sense of going out of oneself (Gauthier 2011) and being in a 'special world inhabited by exceptionally intense forces' (Durkheim 1995, 220).

Altered states of consciousness come in multiple varieties (Lapassade 1990). At departies, most participants aim for mind alterations that fall within the experiential spectrum of what may be called 'collective effervescence' (Durkheim 1995), meaning states of intoxication marked by high levels of emotional energy combined with strong fellow feelings and antinomian behaviors (Reference removed 2013c). This is an intense experience, one of being alive, free from restraints, and part of a large and powerful whole (Malbon 1999; Durkheim 1995; Reference removed 2013c). These altered states of consciousness are one of the key goals of departies, perhaps even their raison d'être (Malbon 1999, 105).

Departies are collective celebrations where participants are brought closely together in the same place, both during their waking hours and often also during their sleep, which tends to take place in shared tents and hotel rooms. This physical proximity per se is a strong stimulant that can be mood- and mind-altering (Wellman, Corcoran, and Stockly-Meyerdirk 2014). When multiple bodies come close to one another in ritual situations, there is a 
tendency for the affective flows to run faster and for the mutual awareness to increase (Collins 2004, 34). Moreover, the combination of proximity and sustained bodily movement generates heat, which may contribute to dehydration and disorientation while legitimizing minimal clothing, erotized behavior, and sexual experimentation (Thomas 2005; Diken and Laustsen 2004; Reference removed 2011).

Alcohol and other drugs are key factors that enable the experiential changes at departies. For example, when young tourists travel to nightlife destinations, alcoholic beverages are accessible and consumed nearly everywhere and at all hours (Sönmez et al. 2013). There are drinks on sale onboard the airplane as well as in restaurants, hotel rooms, by the pool, on the beach, and during organized parties, some of which include all-you-can-drink specials and drinking competitions where large amounts of beer, cocktails, or hard liquor have to be downed as quickly as possible (Sönmez et al. 2013; Briggs 2012; Reference removed 2012). Illicit drugs are also sold quite openly by local drug dealers as well as by public relations workers who want to earn some extra money (Kelly, Hughes, and Bellis 2014, 10057). If substances are overpriced or difficult to access, departy participants are likely to smuggle them into the scene. For example, strong, cheap liquor may be mixed with sweet drinks and carried in a bottle hidden in a pocket (Reference removed forthcoming). Intoxication is part of the package, much to the satisfaction of the participants, who belong to a generation with a strong and recurrent will to experiment with altered states of consciousness (Measham and Brain 2005, 266-7).

Some participants deliberately engage in high-risk activities, such as poly-drug use or fights, out of a desire to get away from 'mundane reality' and enter 'a world of sensual immediacy' (Lyng 2005, 24). The affective grip of these situations may be so intense that it helps those experiencing it to momentarily forget about the drama in their everyday lives. The engagement in high-risk activities may afford rewarding experiences, including acute thrill, 
flow, shared transcendence, togetherness, and euphoria (Cronin, McCarthy, and Collins 2014), and allow risk-takers to show mastery of dangerous situations, to gain recognition for their exploits, and eventually to get good stories from these escapades (Reference removed 2013a). Participants may derive immediate pleasure from purposively plunging into situations that verge on chaos and harm, but for most young people, the fun stops if somebody is severely hurt, whether physically or emotionally (Martinic and Measham 2008, 9). Many departy participants voluntarily take risks, but they prefer to come home in one piece (Reference removed).

However, the experiential changes at departies are not provoked simply by a few single factors. One of the main reasons that departies have such strong effects is that they last for several days or weeks on end. Sustained celebrations can do 'a sort of violence to the individual's body and mind' and disrupt 'their normal functioning' (Durkheim 1995, 228). The sustained engagement in highly stimulating activities serves to destabilize the bodies and minds of the participants so as to enable them to transgress the confines of their ordinary consciousness (Malbon 1999, 106; St John 2008; Reference removed 2015c). The noise, music, swarming crowds, dancing, lack of sleep, mind-altering substances, sexualized atmosphere, and junk food produce a sensual overstimulation (Gopal 2013, 164) that may provoke a rupture with the ordinary and lead to new ways of experiencing and being in the world (Fontaine and Fontana 1996).

\section{Discussion}

The five departures described in this paper are aspects of the same type of celebration, not a list of independent features. It is the combination and intensity of these departures from everyday life, which constitute a departy: the break with habitual spatial practices, the search for immediate yet memorable gratifications, the playful and scripted deviance from prevailing 
morality, the spectacular performances and stylistic experimentations, and the sustained alterations of consciousness. These five elements all have to be present simultaneously in order for an event to conform to the departy concept.

Departies form a significant break with everyday life, and participants often experience them as exceptional. However, this should not lead to the conclusion that departies are culturally isolated events. They belong to the cultural mainstream (Calafat et al. 2011) and are composed of activities that the participants know well from their home environments and everyday lives. For example, the binge drinking, violence, and casual sex at departies may be unusually frequent, but these activities are certainly not unknown to the participants. Similarly, package tours, road parties, and strip shows may not be a central part of the participants' dayto-day lives, yet these phenomena are within their cultural horizon. In this sense, the present paper supports the argument that departies form extensions of, rather than radical breaks with, regular, everyday leisure activities (Carr 2002).

However, departies certainly have elements of exceptionality. They revolve around mainstream activities, but take many of these activities to a level of excess. This may create something new in the lives of the participants. Departies are widely understood as windows of opportunity for engaging in risky pleasures, such as binge drinking for days on end, and for having unprotected sex (Apostolopoulos, Sönmez, and Yu 2002; Maticka-Tyndale, Herold, and Mewhinney 1998; Bellis et al. 2004). Some participants also seize the opportunity to partake in behaviors of a more criminal character, such as paying for sex or trying an illegal drug for the first time (Bellis et al. 2003; Bellis et al. 2009; Reference removed 2010, 2011).

Departies form a risky but also highly valued leisure activity for young people across the world. This poses a number of challenges to public health agencies, and it also raises a series of ethical questions: For is it morally tenable to prevent risky activities that people find pleasurable? How can we dissuade people from engaging in risky activities, when they are 
hell-bent on doing just that? And might there be a way to reduce the harms without reducing the perceived benefits of departies? There are many answers to these questions, but there appears to be growing consensus among researchers that health promotion at departy spaces (e.g. festivals and nightlife resorts) should be based on collaborative strategies that involve a broad range of actors, including the authorities in home and destination areas, health services, travel agencies, venue owners, bartenders, security staff, as well as the departy participants themselves (Hughes and Bellis 2006; Sönmez et al. 2013; Kelly, Hughes, and Bellis 2014; Reference removed 2009).

The general characteristics of departies, which we have described, are not intended to conceal individual differences or conflicts between the participants. Some participants may exercise relative caution, whereas others may attempt to overturn and redefine core elements of a departy, for example by emphasizing abstinence from popular substances or introducing previously banned ones. Friendship groups are also likely to establish differentiated social roles, and conflicts between participants are at least as likely at departies as elsewhere. Moreover, the spatial, temporal, moral, stylistic, and experiential departures offer opportunities to experiment with different modes of self-expression, and witnessing other participants engage in seemingly extreme activities offers even dedicated participants opportunities to draw symbolic boundaries that position themselves as moderate. Departies are interesting contexts for studies of expressions of identity and group dynamics, not only in and of themselves but also in comparison with shorter and more regular celebrations closer to home.

Alcohol, drug and public health researchers tend to portray departies from a critical angle, focusing on health problems, crime, and economic costs. There certainly are many problematic sides to departies, including the short- and long-term health risks, the profits that go to local drug dealers and other criminals, the burden on local healthcare services and on 
police forces, and the sexism that prevails at many events. Nevertheless, if we wish to understand the socio-psychological dynamics and attractions of departies, it is crucial to study them in an open-minded and nonjudgmental manner. This involves analyzing the modified moral orders of such events without holding them to predefined standards (which is not the same as refraining from drawing political conclusions from findings).

Given the centrality of partying to the lives of young people across the world, we believe that it would be possible, and helpful, to build a comprehensive typology of celebrations among youth. In addition to departies, such a typology should take into account shorter events, such as New Year's Eve celebrations, more routine parties, such as weekend binge drinking, and family-centered celebrations where intoxicants may have a secondary role. A comprehensive typology of youth parties would be valuable not only for youth researchers, but also for researchers engaged in promoting safer and healthier nightlife environments.

\section{References}

Andrews, Hazel. 2009. "“Tits Out for the Boys and No Back Chat": Gendered Space on Holiday." Space and Culture 12 (2):166-182.

Andriotis, Konstantinos 2010. "Brits behaving badly: template analysis of newspaper content." International Journal of Tourism Anthropology 1 (1):15-34.

Apostolopoulos, Y, S Sönmez, and Chong H Yu. 2002. "HIV-risk behaviours of American spring break vacationers: a case of situational disinhibition?" International journal of STD \& AIDS 13 (11):733-743.

Bataille, Georges. 2001. Eroticism. Translated by Mary Dalwood. London: Penguin.

Bell, D. 2008. "Destination drinking: Toward a research agenda on alcotourism." Drugs-Education Prevention and Policy 15 (3):291-304.

Bellis, M. A., K. Hughes, A. Calafat, M. Juan, and S. Schnitzer. 2009. "Relative Contributions of Holiday Location and Nationality to Changes in Recreational Drug Taking Behaviour: A Natural Experiment in the Balearic Islands." European Addiction Research 15 (2):78-86.

Bellis, MA, K Hughes, R Thomson, and A Bennett. 2004. "Sexual behaviour of young people in international tourist resorts." Sex Transm Infect 80:43 - 47. 
Bellis, Mark A., Gerry Hale, Andrew Bennett, Mohammad Chaudry, and Mary Kilfoyle. 2000. "Ibiza uncovered: changes in substance use and sexual behaviour amongst young people visiting an international night-life resort." International Journal of Drug Policy 11 (3):235-244.

Bellis, Mark A., Karen Hughes, Andrew Bennett, and Roderick Thomson. 2003. "The role of an international nightlife resort in the proliferation of recreational drugs." Addiction 98 (12):1713-1721.

Bey, Hakim. 1991. T.A.Z.: The Temporary Autonomous Zone, Ontological Anarchy, Poetic Terrorism. New York: Autonomedia.

Bhardwa, Bina. 2014. "The Construction of Dance Consumer Identities: An Exploration of Drug Use, Digital Technologies and Control in Three Dance Settings." Lancaster University.

Briggs, Daniel. 2012. "A phenomenological account of deviance and risk on holiday: British youth and the consumer experience in Ibiza." In New directions in crime and deviance, edited by S. Winslow and R. Atkinson. London: Routledge.

Briggs, Daniel. 2013. Deviance and risk on holiday: An ethnography of British tourists in Ibiza. London: Palgrave Macmillan.

Briggs, Daniel, and Tim Turner. 2012. "Understanding British youth behaviors on holiday in Ibiza." International Journal of Culture, Tourism and Hospitality Research 6 (1):81-90.

Briggs, Daniel, Tim Turner, Kerri David, and Tara De Courcey. 2011. "British youth abroad: some observations on the social context of binge drinking in Ibiza." Drugs and Alcohol Today 11 (1):26-35.

Brown, Lorraine, and Yvonne Simone Stephan. 2013. "Anonymous and uninhibited: sexual encounters during the international sojourn." Journal of Tourism and Cultural Change 11 (12):35-47.

Bøhling, Frederik. 2015. "Alcoholic assemblages: Exploring fluid subjects in the night-time economy." Geoforum 58:132-142.

Calafat, Amador, Nicole Blay, Mark Bellis, Karen Hughes, Anna Kokkevi, Fernando Mendes, Barbara Cibin, Philipe Lazarov, Lubomira Bajcarova, and George Boyiadjis. 2011. Tourism, nightlife and violence: a cross cultural analysis and preventive recommendations. In European Commission. Directorate-General Justice. Palma de Mallorca: Irefrea.

Carr, Neil. 2002. "The Tourism-Leisure Behavioural Continuum." Annals of Tourism Research 29 (4):972-986.

Collins, Randall. 2004. Interaction ritual chains. Princeton: Princeton University Press.

Cronin, James M., Mary McCarthy, and Alan Collins. 2014. "Creeping edgework: carnivalesque consumption and the social experience of health risk." Sociology of Health \& Illness 36 (8):1125-1140.

Dickerson, Thomas A. 1996. "How Safe Are Student Tours." Travel Law Journal (3):97-99.

Diken, Bülent, and Carsten Bagge Laustsen. 2004. "Sea, sun, sex and the discontents of pleasure." Tourist Studies 4 (2):99-114.

Dilkes-Frayne, Ella. in press. "Drugs at the campsite: Socio-spatial relations and drug use at music festivals." International Journal of Drug Policy. 
Duff, Cameron. 2008. "The pleasure in context." International Journal of Drug Policy 19 (5):384-392.

Duff, Cameron. 2010. "On the role of affect and practice in the production of place." Environment and planning. D, Society and space 28 (5):881-895.

Durkheim, Emile. 1995. The Elementary Forms of Religious Life. Translated by Karen E. Fields. New York: Free Press.

Eberhardt, David M. 2007. "Facing up to facebook." About Campus 12 (4):18-26.

Ellen, Barbara 2014. "Mamading in Magaluf: this is not a tale of broken Britain. It's far, far sadder." Accessed 16 June. http://www.theguardian.com/commentisfree/2014/jul/05/mamadingmagaluf-alcohol-sex-exploitation.

Fontaine, Astrid, and Caroline Fontana. 1996. Raver. Paris: Anthropos.

Forsyth, Craig J. 1992. "Parade strippers: A note on being naked in public." Deviant Behavior 13 (4):391-403.

Frank, Arthur W. 2013. The wounded storyteller: Body, illness, and ethics. Chicago: University of Chicago Press.

Gauthier, François. 2011. "Les HeeBeeGeeBee Healers au Festival Burning Man: Trois récits de guérison." Ethnologies 33 (1):191-215.

Goffman, Erving. 1986. Stigma: Notes on the management of spoiled identity. New York: Simon \& Schuster.

Gopal, Nirmala. 2013. "Music, trance and dance in the Thaipusam Kavady festival: Reflections of a select group of South Africans." Journal of Sociology and Social Anthropology 4 (1/2):159166.

Goulding, Christina, Avi Shankar, and Richard Elliott. 2002. "Working Weeks, Rave Weekends: Identity Fragmentation and the Emergence of New Communities." Consumption Markets \& Culture 5 (4):261-284.

Hier, Sean P. 2002. "Raves, Risks and the Ecstacy Panic: A Case Study in the Subversive Nature of Moral Regulation." Canadian Journal of Sociology 27 (1).

Hitlin, Steven. 2007. "Doing good, feeling good: Values and the self's moral center." The Journal of Positive Psychology 2 (4):249-259.

Hughes, K., and M. A. Bellis. 2006. "Sexual behaviour among casual workers in an international nightlife resort: a case control study." Bmc Public Health 6.

Hughes, Karen, Mark A Bellis, Gayle Whelan, Amador Calafat, Montse Juan, and Nicole Blay. 2009. "Alcohol, drugs, sex and violence: health risks and consequences in young British holidaymakers to the Balearics." Adicciones 21 (4):265-277.

Hughes, Karen, Mark A. Bellis, Amador Calafat, Montse Juan, Susanne Schnitzer, and Zara Anderson. 2008. Predictors of violence in young tourists: a comparative study of British, German and Spanish holidaymakers. Vol. 18. Journal Article.

Jaimangal-Jones, Dewi, Annette Pritchard, and Nigel Morgan. 2010. "Going the distance: locating journey, liminality and rites of passage in dance music experiences." Leisure Studies 29 (3):253-268. 
Jankowiak, William, and C. Todd White. 1999. "Carnival on the Clipboard: An Ethnological Study of New Orleans Mardi Gras." Ethnology 38 (4):335-349.

Jayne, M., C. Gibson, G. Waitt, and G. Valentine. 2012. "Drunken mobilities: Backpackers, alcohol, 'doing place'." Tourist Studies 12 (3):211-231.

Josiam, Bharath M., J. S. Perry Hobson, Uta C. Dietrich, and George Smeaton. 1998. "An analysis of the sexual, alcohol and drug related behavioural patterns of students on spring break."

Tourism Management 19 (6):501-513.

Kelly, Danielle, Karen Hughes, and Mark A Bellis. 2014. "Work hard, party harder: drug use and sexual behaviour in young British casual workers in ibiza, Spain." International journal of environmental research and public health 11 (10):10051-10061.

Khan, F, J Ditton, L Elliott, E Short, A Morrison, S Farrall, L Gruer, S Carter, and S Clift. 2000. "EscapeEs: How the ecstasy using holidaymaker eludes post-modern theory." In Tourism and Sex: Culture, Commerce and Coercion, edited by S Carter and S Clift, 221-235. London: Cassell.

Korine, Harmony. 2012. Spring Breakers. New York: A24.

Lapassade, Georges. 1990. La Trance. Paris: PUF.

Lyng, Stephen. 2005. Edgework: the sociology of risk taking. New York: Routledge.

Maffesoli, Michel. 1985. L'Ombre de Dionysos. Contribution à une sociologie de l'orgie. Paris: Le Livre de Poche.

Maffesoli, Michel. 1989. "The sociology of everyday life (epistemological elements)." Current Sociology 37 (1):1-16.

Maffesoli, Michel. 2003. Notes sur la postmodernité. Le lieu fait lien. Paris: Editions du Félin.

Malbon, Ben. 1999. Clubbing: Dancing, Ecstasy, Vitality. London: Taylor \& Francis.

Mann, Mark. 2013. The community tourism guide: Exciting holidays for responsible travellers. New York: Routledge.

Martinic, Marjana, and Fiona Measham. 2008. "Extreme drinking." In Swimming with Crocodiles: The Culture of Extreme Drinking, edited by Marjana Martinic and Fiona Measham, 1-12. New York: Routledge.

Maticka-Tyndale, Eleanor, Edward S. Herold, and Dawn Mewhinney. 1998. "Casual sex on spring break: Intentions and behaviors of Canadian students." Journal of Sex Research 35 (3):254264.

Maticka-Tyndale, Eleanor, Edward S. Herold, and Martin Oppermann. 2003. "Casual sex among australian schoolies." The Journal of Sex Research 40 (2):158-169.

Max, Tucker. 2012. Hilarity Ensues. Austin: Blue Heeler.

McRobbie, Angela. 1994. Postmodernism and Popular Culture. London: Routledge.

Measham, Fiona. 2004. "Play space: historical and socio-cultural reflections on drugs, licensed leisure locations, commercialisation and control." International Journal of Drug Policy 15 (56):337-345. 
Measham, Fiona, and Kevin Brain. 2005. "'Binge' drinking, British alcohol policy and the new culture of intoxication." Crime, media, culture 1 (3):262-283.

Measham, Fiona, and Karenza Moore. 2009. "Repertoires of distinction: Exploring patterns of weekend polydrug use within local leisure scenes across the English night time economy." Criminology and Criminal Justice 9 (4):437-464.

Miao, Li, Xinran Lehto, and Wei Wei. 2013. "The Hedonic Value of Hospitality Consumption: Evidence From Spring Break Experiences." Journal of Hospitality Marketing \& Management 23 (2):99-121.

Milhausen, Robin R., Michael Reece, and Bilesha Perera. 2006. "A theory-based approach to understanding sexual behavior at Mardi Gras." The Journal of Sex Research 43 (2):97-106.

Monterrubio, J. Carlos, Bharath M. Josiam, and Jennifer Duncan. 2015. "Tequila at Sunrise: Spring Break Travel Motivations and Risk Behaviors of American Students in Acapulco, Mexico." Hospitality Review 31 (4):7.

Niland, Patricia, Antonia C. Lyons, Ian Goodwin, and Fiona Hutton. 2014. "'See it doesn't look pretty does it?": Young adults' airbrushed drinking practices on Facebook." Psychology \& Health:130 .

O'Grady, A. (2012). 2012. "Spaces of Play The Spatial Dimensions of Underground Club Culture and Locating the Subjunctive." Dancecult: Journal of Electronic Dance Music Culture 4 (1):86106.

Patrick, Megan E, Nicole Morgan, Jennifer L Maggs, and Eva S Lefkowitz. 2011. "“I Got Your Back”: Friends' Understandings Regarding College Student Spring Break Behavior." Journal of Youth and Adolescence 40 (1):108-120.

Redmon, David. 2002. "Testing informal social control theory: Examining lewd behavior during Mardi Gras." Deviant Behavior 23 (4):363-384.

Redmon, David. 2003. "Playful deviance as an urban leisure activity: secret selves, self-validation, and entertaining performances." Deviant Behavior 24 (1):27-51.

Reference removed. 2008.

Reference removed. 2009.

Reference removed. 2010.

Reference removed. 2011.

Reference removed. 2012.

Reference removed. 2013a.

Reference removed. 2013b.

Reference removed. 2013c.

Reference removed. 2015a.

Reference removed. 2015b. 
Reference removed. 2015c.

Reference removed. forthcoming.

Reynolds, S. 1998. Energy flash: A journey through rave music and dance culture. London: Picador.

Ribeiro, Nuno F, Careen M Yarnal, Garry E Chick, and E Paul Durrenberger. 2009. "Perceptions of Spring Break and Spring Break Experiences: A Strange Dichotomy."

Robards, Brady, and Andy Bennett. 2011. "MyTribe: Post-subcultural Manifestations of Belonging on Social Network Sites." Sociology 45 (2):303-317.

Sande, Allan. 2002. "Intoxication and rite of passage to adulthood in Norway." Contemporary Drug Problems 29 (2):277-240.

Shields, Rob. 1990. "The 'System of Pleasure': Liminality and the Carnivalesque at Brighton." Theory, Culture \& Society 7 (1):39-72.

St John, Graham. 2001. "Alternative Cultural Heterotopia and the Liminoid Body: Beyond Turner at ConFest." The Australian Journal of Anthropology 12 (1):47-66.

St John, Graham. 2008. "Trance tribes and dance vibes: Victor Turner and electronic dance music culture." In Victor Turner and contemporary cultural performance, edited by Graham St John, $149-73$.

St John, Graham. 2009. Technomad: Global raving countercultures. London: Equinox Publishing.

Sönmez, Sevil, Yorghos Apostolopoulos, Antonis Theocharous, and Kelley Massengale. 2013. "Bar crawls, foam parties, and clubbing networks: Mapping the risk environment of a Mediterranean nightlife resort." Tourism Management Perspectives 8:49-59.

Sönmez, Sevil, Yorghos Apostolopoulos, Chong Ho Yu, Shiyi Yang, Anna Mattila, and Lucy C Yu. 2006. "Binge drinking and casual sex on spring break." Annals of Tourism Research 33 (4):895-917.

Tan, Q. H. 2013. "Flirtatious geographies: clubs as spaces for the performance of affective heterosexualities." Gender Place and Culture 20 (6):718-736.

Thomas, Michelle. 2005. "'What happens in Tenerife stays in Tenerife': Understanding women's sexual behaviour on holiday." Culture, Health \& Sexuality 7 (6):571-584.

Thorpe, Holly. 2011. "'Sex, drugs and snowboarding': (il)legitimate definitions of taste and lifestyle in a physical youth culture." Leisure Studies 31 (1):33-51.

Thurnell-Read, Thomas. 2011. "Off the leash and out of control: masculinities and embodiment in Eastern European stag tourism." Sociology 45 (6):977-991.

Thurnell-Read, Thomas. 2012. "What Happens on Tour: The Premarital Stag Tour, Homosocial Bonding, and Male Friendship." Men and Masculinities 15 (3):249-270.

Tiësto. 2007. In search of sunrise 6 - Ibiza. Black Hole.

Tremlett, Giles 2010. "Spanish authorities warn holidaymakers of 'balconing' dangers." The Guardian, Last Modified 3 June 2014 Accessed 20 May 2015.

http://www.theguardian.com/world/2010/aug/11/spanish-authorities-balconies-holidaymakerswarning. 
Truong, Jasmine. 2015. "Feeling connected online and offline, The use of WhatsApp in the urban night out experiences of young people." Club Health Conference, Lisbon.

Turner, Victor W. 1977. "Variations on a theme of liminality." In Secular Ritual, edited by Sally F. Moore and Barbara G. Myerhoff, 36-52. Assen: Van Gorcum.

van Gennep, Arnold 1960. The Rites of Passage. London: Routledge \& Kegan Paul.

Weber, Max. 2011. ""Objectivity" in Social Science and Social Policy." In Methodology of Social Sciences: Max Weber, edited by Edward A Shils and Henry A Finch, 49-112. New Brunswick: Transaction Publishers.

Wellman, James K., Katie E. Corcoran, and Kate Stockly-Meyerdirk. 2014. "“God Is Like a Drug...”: Explaining Interaction Ritual Chains in American Megachurches." Sociological Forum 29 (3):650-672. 